\title{
Infrared thermography and capillaroscopy in the diagnosis of Raynaud's phenomenon
}

\author{
Jan Sternbersky ${ }^{a}$, Martin Tichy ${ }^{\mathrm{a}}$, Jana Zapletalova ${ }^{\mathrm{b}}$
}

\begin{abstract}
Aims. Raynaud's phenomenon (RP) is a relatively common disease. There are two distinct forms of RP - primary (PRP), where no other associated diseases are present, and secondary (SRP), where RP is associated with other diseases. It can be challenging to differentiate between RP and other diseases through medical history alone, due to the episodic nature of RP. Objective analysis of anamnestic data was performed in our study using infrared thermography (IRT) and a cold pressor test (CPT). Capillaroscopy was performed to assess morphological changes in the acral circulation. Methods. Patients with a history of cold hands were included in the study. IRT was performed before and after the CPT, and then capillaroscopy was performed. The results (including epidemiologic data) were statistically evaluated. Results. A total of 150 patients were included in the study. Summarisation of the results from the IRT and capillaroscopy determined the final diagnosis - $4.7 \%$ acrocyanosis, $10.7 \%$ physiologic findings, 31.3\% PRP, $29.3 \%$ borderline SRP and $24 \%$ SRP. The coldest fingers following the CPT were, in most patients, the $2^{\text {nd }}$ and $3^{\text {rd }}$ fingers. The correlation between the presence of connective tissue disease and the diagnosis of borderline SRP and SRP was significant $(P=0.0001)$.

Conclusions. Using the combination of the IRT and capillaroscopy in the diagnostic algorithm for RP has its justification. IRT distinguishes healthy patients from patients with RP, and capillaroscopy can then be used to differentiate PRP from SRP. IRT can also detect which fingers are more affected, and then these can direct the focus of capillaroscopy.
\end{abstract}

Key words: Raynaud's phenomenon, infrared thermography, cold pressor test, capillaroscopy, connective tissue disease

Received: September 4, 2019; Revised: May 25, 2020; Accepted: July 7, 2020; Available online: July 15, 2020 https://doi.org/10.5507/bp.2020.031

(c) 2021 The Authors; https://creativecommons.org/licenses/by/4.0/

${ }^{a}$ Department of Dermatology and Venereology, Faculty of Medicine and Dentistry, Palacky University Olomouc and University Hospital Olomouc, Czech Republic

${ }^{b}$ Department of Medical Biophysics, Faculty of Medicine and Dentistry, Palacky University Olomouc, Czech Republic Corresponding author: Jan Sternbersky, e-mail:jan.sternbersky@fnol.cz

\section{INTRODUCTION}

Acral perfusion disorders are relatively frequent diseases that are manifested by subjective feelings of cold hands or feet. Raynaud's phenomenon (RP) is a typical representative of this type of disorder ${ }^{1,2}$. We distinguish between primary Raynaud's phenomenon (PRP), which lacks further associated disease, and secondary Raynaud's phenomenon (SRP), which is the manifestation of another disease and can have a major impact on patients' health $^{3.5}$ (Table 1) (ref. ${ }^{6}$ ). Raynaud's phenomenon is characterised by repeated attacks of colour changes of body extremities, mostly provoked by cold. A typical clinical picture of an attack of the disease is a so-called triphasic course of colour changes in the extremities. The initial phase is whitening, which is the most typical finding for RP and is caused by vasospasm. This phase is followed by a cyanotic phase, which is induced by tissue hypoxia. The last stage is redness caused by tissue reperfusion hyperaemia. We most often notice the colour changes on the fingers ${ }^{6,7}$. Attacks of the disease are strictly episodic and alternate with periods without any RP symptoms. The prevalence of RP is $3-5 \%$ globally with a higher prevalence in countries with a colder climate. The median age of the first attack of the disease is 14 years ${ }^{8,9}$. A clinical picture of RP with a triphasic course of colour changes is typical for RP; however, without direct observation of such an attack, we must rely on patients' anamnestic data, which can be rather distorted. Various types of examination can be used to verify RP. By means of the cold pressor test (CPT) in combination with an analysis of temperature via infrared thermography (IRT), we can imitate the most common trigger factors of the disease and evaluate the acral perfusion functionality ${ }^{10}$. Assessment of morphological changes of acral perfusion is possible with the use of capillaroscope $e^{11-13}$.

Timely diagnosis of RP plays a crucial role in its treatment, especially in patients with latent connective tissue disease, where RP manifestations may precede, even by years, the systemic progression of this serious disease $\mathrm{e}^{14-17}$.

Goals

There were three basic goals for our experimental work:

a) to epidemiologically document the patient population with acral perfusion disorders,

b) to use IRT and CPT to objectivise hand acral perfusion disorders 
Table 1. Overview of the most frequent causes of SRP $\left(\right.$ ref. $\left.^{6}\right)$.

\begin{tabular}{|c|c|}
\hline $\begin{array}{l}\text { Autoimmune diseases } \\
\text { - systemic scleroderma } \\
\text { - rheumatoid arthritis } \\
\text { - Sjögren's syndrome } \\
\text { - systemic lupus erythematosus } \\
\text { - dermatomyositis }\end{array}$ & $\begin{array}{l}\text { - antisynthetase syndrome } \\
\text { - mixed connective tissue disorder } \\
\text { - undifferentiated connective tissue disease } \\
\text { - antiphospholipid syndrome }\end{array}$ \\
\hline $\begin{array}{l}\text { Vasculitides } \\
\text { - granulomatosis with polyangiitis } \\
\text { - eosinophilic granulomatosis with polyangiitis } \\
\text { - polyarteritis nodosa } \\
\text { - microscopic polyangiitis } \\
\text { - Behçet's disease } \\
\text { - Takayasu arteritis }\end{array}$ & $\begin{array}{l}\text { - Henoch-Schönlein purpura } \\
\text { - thrombangiitis obliterans } \\
\text { - Kawasaki disease } \\
\text { - cryoglobulinaemic vasculitis } \\
\text { - giant cell arteritis }\end{array}$ \\
\hline $\begin{array}{l}\text { Haematological diseases causing disorders in rheo } \\
\text { - cryoglobulinaemia } \\
\text { - cryofibrinogenaemia } \\
\text { - cold agglutinin disease } \\
\text { - paraproteinaemia }\end{array}$ & $\begin{array}{l}\text { logical properties of blood } \\
\text { - polycythaemia vera } \\
\text { - hyperviscosity syndrome } \\
\text { - Waldenström macroglobulinaemia } \\
\text { - congenital thrombophilic states }\end{array}$ \\
\hline $\begin{array}{l}\text { Compression and obstruction syndromes } \\
\text { - atherosclerosis } \\
\text { - microembolisation } \\
\text { - diabetic microangiopathy }\end{array}$ & $\begin{array}{l}\text { - upper thoracic aperture syndrome } \\
\text { - cervical rib syndrome } \\
\text { - carpal tunnel syndrome }\end{array}$ \\
\hline $\begin{array}{l}\text { Neurological diseases } \\
\text { - reflex sympathetic dystrophy } \\
\text { - hemiplegia } \\
\text { - syringomyelia }\end{array}$ & $\begin{array}{l}\text { - poliomyelitis } \\
\text { - discopathy }\end{array}$ \\
\hline $\begin{array}{l}\text { Infectious diseases } \\
\text { - hepatitis B } \\
\text { - hepatitis C } \\
\text { - HIV/AIDS }\end{array}$ & $\begin{array}{l}\text { - } \text { cytomegalovirus } \\
\text { - parvovirus B19 }\end{array}$ \\
\hline $\begin{array}{l}\text { Occupational diseases } \\
\text { - vibration disease } \\
\text { - hypothenar hammer syndrome } \\
\text { - vinyl chloride disease }\end{array}$ & \\
\hline $\begin{array}{l}\text { Other diseases associated with RP } \\
\text { - malignancies: pheochromycytoma, carcinoid, } \\
\text { leukaemia, lymphomas, solid tumours } \\
\text { - hypothyroidism } \\
\text { - pulmonary hypertension }\end{array}$ & $\begin{array}{l}\text { - } \text { primary biliary cholangitis } \\
\text { - POEMS syndrome } \\
\text { - toxic oil syndrome } \\
\text { - lesions caused by cold or radiation }\end{array}$ \\
\hline $\begin{array}{l}\text { Medicines and drugs } \\
\text { - cisplatin } \\
\text { - bleomycin } \\
\text { - beta-blockers } \\
\text { - interferon } \\
\text { - minocycline } \\
\text { - bromocriptine } \\
\text { - sulfasalazine } \\
\text { - cyclosporine }\end{array}$ & $\begin{array}{l}\text { - methysergide } \\
\text { - ergotamine } \\
\text { - clonidine } \\
\text { - nicotine } \\
\text { - amphetamines } \\
\text { - cocaine } \\
\text { - cannabis }\end{array}$ \\
\hline
\end{tabular}

c) to distinguish between PRP and SRP in combination with capillaroscopic examination.

\section{MATERIALS AND METHODS}

\section{Infrared thermographic examination of hands}

All hand temperature measurements were conducted using a Flir B-360 portable thermal imaging camera, made by FLIR Systems company (Stockholm, Sweden). Using the thermal imaging camera, infrared radiation was recorded and converted to a visual image - a thermogram. A rainbow theme was used to distinguish between individual temperature differences. In this palette, the red or white colours represent the highest temperature values, while blue or black represent the lowest values. The minimum temperature difference that the instrument can distinguish is $0.1{ }^{\circ} \mathrm{C}$.

To ensure stable conditions, the room was air-conditioned to the required temperature at least $30 \mathrm{~min}$ before 
starting the test. The average room temperature during the measurement was $22.3^{\circ} \mathrm{C}$, which corresponds to normal room temperature and does not lead to activation of central thermoregulation mechanisms. The average relative air humidity during all measurements was $50 \%$. The camera was placed on a tripod such that the angle between the measured object and the thermal imaging camera was equal to $60^{\circ}$. The distance between the thermal imaging camera and the hands was one metre. To maximise the reproducibility rate of the IRT results, the examination was conducted in accordance with the recommendations of the Glamorgan Protocol, which defines the conditions under which given areas of the human body can be examined $^{18,19}$.

Before the beginning of the examination, the patients were acclimatised in the examination room for $30 \mathrm{~min}$ in a position in which the subsequent measurements were carried out. The patients sat in a comfortable position on a chair with adjustable seating height with their hands laid on the examination table. During all examinations, the hands were laid palm down on a pad made of polystyrene. After adequate acclimatisation, a so-called resting hands thermogram was created. This was followed by a cold test, which consisted of the immersion of hands up to the level of wrists into cold water for $5 \mathrm{~min}$. The water temperature for all tests was $8.8^{\circ} \mathrm{C}$ on average, with a median of 9 ${ }^{\circ} \mathrm{C}$. The patients then put their hands back on the pad of the examination table, and thermograms were taken at regular intervals - once immediately after pulling the hands out of water and again after 5, 10, 20 and $30 \mathrm{~min}$. The acquired thermograms were then processed by computer technology. The mean temperature in the region
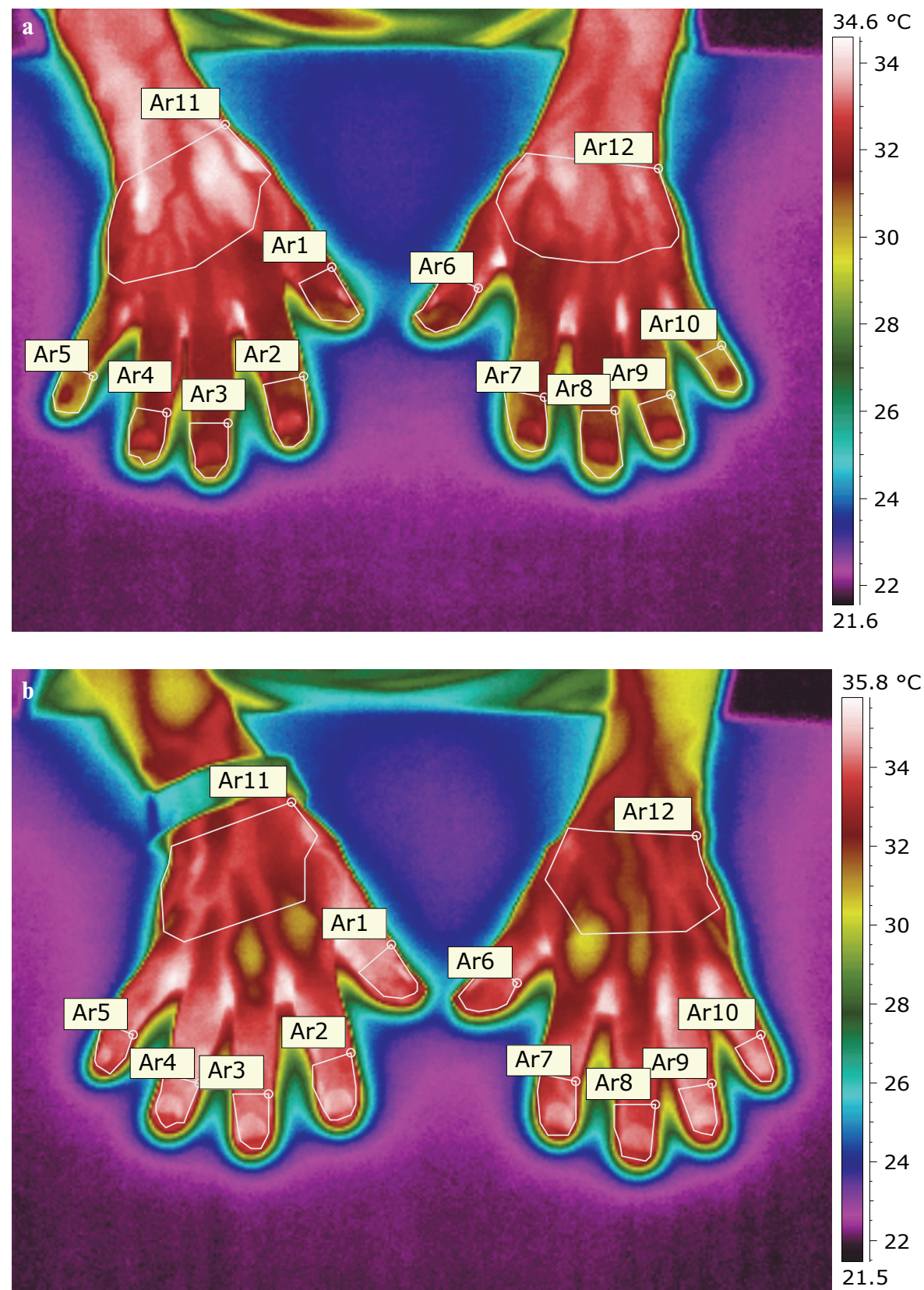

Fig. 1. Physiological finding during the IRT examination.

1a. Thermogram before CPT. No evidence of acral perfusion disorder - all fingers had a temperature $>29^{\circ} \mathrm{C}$.

1b. Thermogram $30 \mathrm{~min}$ after CPT. No evidence of acral perfusion disorder - all fingers had a temperature $>29^{\circ} \mathrm{C}$. 

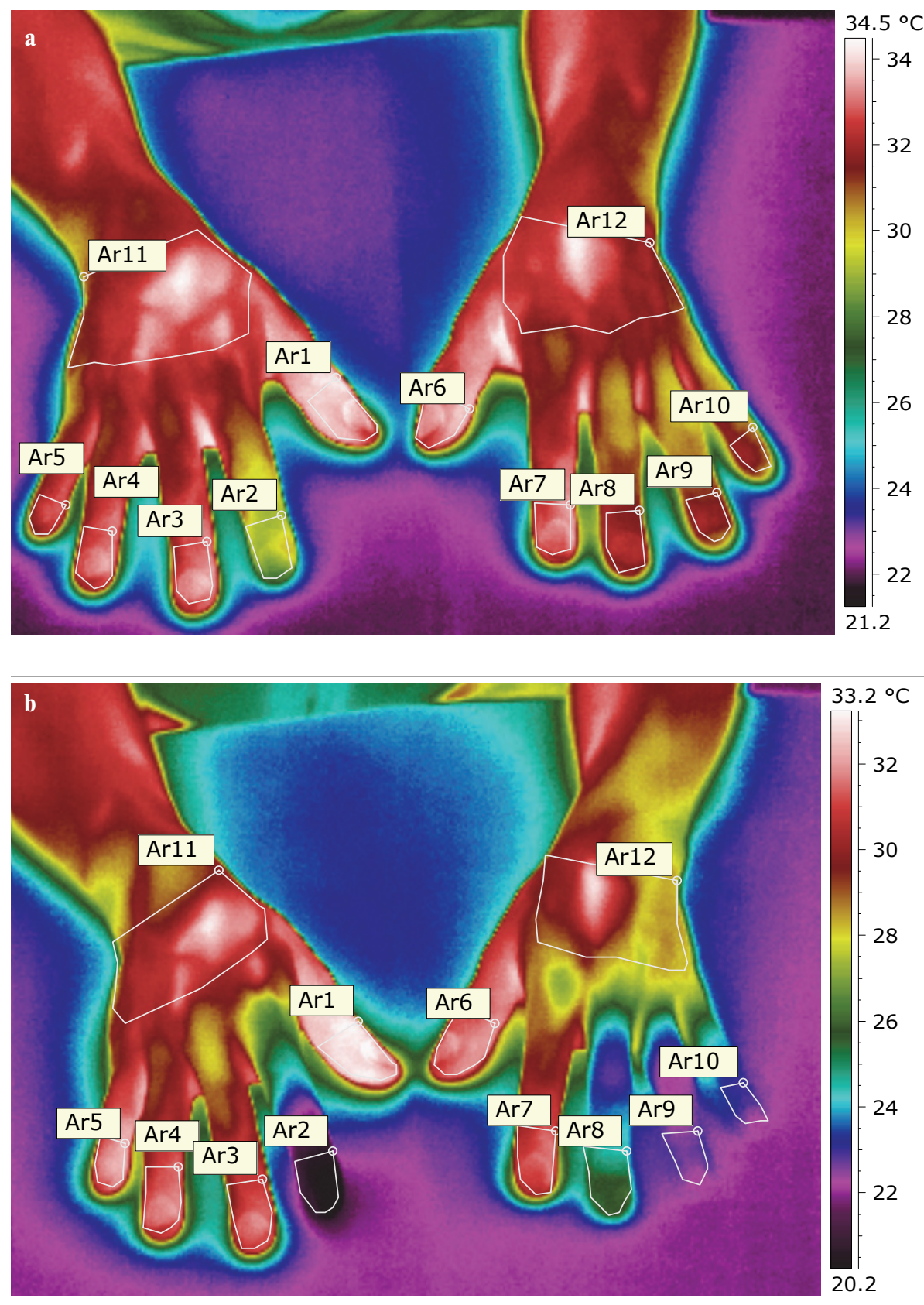

Fig. 2. RP finding during IRT examination.

2a. Thermogram before CPT. No evidence of acral perfusion disorder - all fingers had a temperature $>29^{\circ} \mathrm{C}$.

2b. Thermogram $30 \mathrm{~min}$ after CPT. Detection of hypoperfusion of the $2^{\text {nd }}$ right hand finger and the $3^{\text {rd }}-5^{\text {th }}$ left hand fingers, with temperatures of $<29^{\circ} \mathrm{C}$.

of the distal phalanges of the individual fingers, defined as the area between the distal end of the nail and the interphalangeal articulation, was compared in all patients. Finger temperatures were compared both with regards to lateral differences and, especially, in response to the CPT. The key values were the finger temperatures read after acclimatisation and the finger temperatures read $30 \mathrm{~min}$ after being subjected to the CPT. In this way, a 20 temperature values were obtained. Of these, the so-called distal difference parameter was obtained, which served to evaluate by how many degrees Celsius the temperature of the individual fingers changed. The distal difference was calculated by subtracting the finger temperature value before the CPT from the finger temperature after the CPT. Negative distal difference values indicated that, after the CPT action, the original temperature was not restored. The limit temperature value of the distal finger phalanges, which distinguishes a physiological finding from a pathological one, was set at $29^{\circ} \mathrm{C}$. This value was obtained by analysing the temperature of distal finger phalanges in a control group of 20 healthy probands, where $29{ }^{\circ} \mathrm{C}$ was the lowest value measured. Each finger was individually related to this limit value, considering that even a single finger with a temperature lower than $29^{\circ} \mathrm{C}$ was sufficient to determine the finding as pathological. By setting the $29^{\circ} \mathrm{C}$ threshold, four possible IRT examination outcomes 
were created in relation to the finger temperature finding before the CPT and 30 min after it was completed. If the finger temperature before and after the CPT was $>29^{\circ} \mathrm{C}$, the finding was assessed as physiological (Fig. 1).

If the finger temperature was $<29^{\circ} \mathrm{C}$ before the CPT but $<29{ }^{\circ} \mathrm{C}$ after, the condition was concluded as being acrocyanosis. In the remaining two cases, when the finger temperature after the CPT did not reach $29^{\circ} \mathrm{C}$, such a finding was assessed as RP (Fig. 2).

Another parameter that was monitored, but that was not one of the key indicators, was the distal-dorsal difference (DDD) that, according to many studies, could suggest a diagnosis of SRP. The value of this parameter was calculated by subtracting the average temperature value of a delimited area of the hand dorsum (the area was delimited distally by metacarpophalangeal joints and proximally by the wrist level) from the average temperature in the area of distal finger phalanges. A DDD value of <-1 was considered pathological ${ }^{20-22}$.

\section{Capillaroscopic examination of hands}

An SZP 1102-T Zoom stereoscopic digital photomicroscope (Arsenal) with image magnification ranging from $7 \mathrm{x}$ to $90 \mathrm{x}$ was used for the examination.

After 30-min acclimatisation in the lab at room temperature, the 2 nd, 3rd and 4th fingers of both hands were examined with the capillaroscope. During our examination, we divided the resulting findings according to the number of pathologies detected into physiological, slightly pathological and pathological. A physiological finding was characterised by long narrow capillary loops in regular arrangement and even density, possibly with the finding of a single pathology (slight winding of the loops, slight dilation of the peak of the capillary loop). A slightly pathological finding was established in borderline cases, where a physiological finding was dominant, but pathological changes were occasionally present on almost every finger examined. A pathological finding thus indicated a greater frequency of capillary loop abnormalities in the form of haemorrhages, dilations, loop windings, and possibly avascular areas and other disorders in the density and regularity of capillary loops $\mathrm{s}^{23,24}$.

\section{Statistical data processing}

Nonparametric tests were used to analyse the data. The association between quantitative parameters was assessed by means of Spearman's rank-order correlation, and the association between qualitative parameters was analysed by Fisher's exact test. The Mann-Whitney U test was used for quantitative parameters. The normality of the data was verified by the Shapiro-Wilk test. All tests were performed at a significance level of 0.05. IBM SPSS Statistics version 22 statistical software was used to analyse the data.

\section{RESULTS}

\section{Epidemiological characteristics of the patient population examined}

In total, 150 patients who were examined in our labs from 2010-2017 were enrolled in the study. The main conditions for inclusion of these patients were a history of RP symptoms characterised by feelings of cold hands, with anamnestic reporting of at least one colour change of fingers (cyanotic or white), and completion of capillaroscopic and IRT examinations in our lab.

Our patient sample comprised $24 \%$ men and $76 \%$ women. The average age was 41.1 years, and the median was 40 years. The average duration of subjective feelings of cold hands was 62.8 months (approximately 5 years), with a median of 36 months ( 3 years). The typical triphasic progression of an attack of the disease was reported by $22 \%$ of patients. Two colour changes were observed in $42.7 \%$ of patients $(4.7 \%$ white and red, $26.7 \%$ white and purple and $11.3 \%$ red and purple). The remaining $35.3 \%$ of patients observed only one colour change $(24 \%$ white and $11.3 \%$ cyanotic colouring). Spearman's rankorder correlation showed no association between either the water temperature during the CPT and the finger temperature measured $30 \mathrm{~min}$ after the test was performed or between the water temperature and the distal difference value. Completely healthy individuals were examined (except for the RP history) as well as patients with many comorbidities. Most of the patients suffered from connective tissue diseases $(21.3 \%)$, neurological disorders, including vibration disease (20\% of patients), and thyroid disease (10\%), which corresponds to well-known SRP aetiological factors $^{14,25,26}$ (Fig. 3).

A professional medical history was completed in 55\% of patients, most of whom were manual workers (57.8\%) and administrative staff (20.5\%). Abuse of nicotine was reported by 47 patients out of 146 respondents, i.e., $32.2 \%$ of the patients.

\section{Results of the IRT examination}

Through infrared thermography, the temperature values of distal finger phalanges were obtained before the CPT and 30 min after CPT completion. Through their differences, the distal difference parameter was then found, and the DDD parameter was also found from the difference in the temperature value of the distal phalange from the mean value of the hand dorsum temperature. The highest measured finger temperature before the CPT was $34.4{ }^{\circ} \mathrm{C}$, and the lowest was $18.7^{\circ} \mathrm{C}$. Thirty min after the $\mathrm{CPT}$, the highest finger temperature was $35.6^{\circ} \mathrm{C}$, and the lowest was $16.5^{\circ} \mathrm{C}$. The highest difference between the finger temperature before the CPT and the temperature measured $30 \mathrm{~min}$ after the CPT was $13.6{ }^{\circ} \mathrm{C}$. The limit temperature for the distinction of a pathological finding from a physiological one was $29{ }^{\circ} \mathrm{C}$. The occurrence of temperatures lower than $29{ }^{\circ} \mathrm{C}$ was more often observed 30 min after the CPT than before it started, which correlates with the finding of RP.

Of the 150 patients examined by IRT, 127 (84.7\%) were diagnosed with RP, 7 (4.7\%) with acrocyanosis, and 
a physiological finding was established in the remaining 16 patients $(10.7 \%)$ (Fig. 4$)$.

Symmetric temperature distribution was apparent after acclimatisation in $34 \%$ of patients, while it was apparent in $43.3 \%$ of patients after CPT completion. The highest absolute finger temperature values were recorded on the 1st finger of the right hand as well as the left hand both before and after the CPT.

The coldest finger after acclimatisation was the 5 th finger of the right hand as well as the left hand. After completing the CPT, the second and third fingers of both hands were the coldest. No relationship was found between finger temperature changes and the dominant hand.

\section{Summarising the results of IRT and capillaroscopic examination}

In the monitored patient population, the physiological finding, acrocyanosis and Raynaud's phenomenon, could be detected by IRT. However, none of the parameters of the IRT examination could reliably distinguish PRP from SRP. Therefore, capillaroscopic examination, which was performed on all the observed patients, was used to establish this difference. Nearly half of the patients (46.7\%) underwent capillaroscopic examination without any pathological findings. The remaining patients were diagnosed

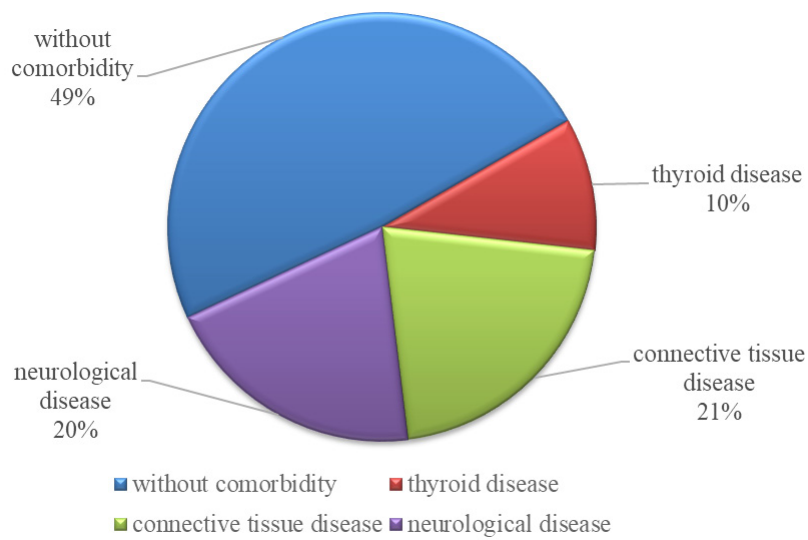

Fig. 3. Incidence of the most common diseases in the observed patient population.

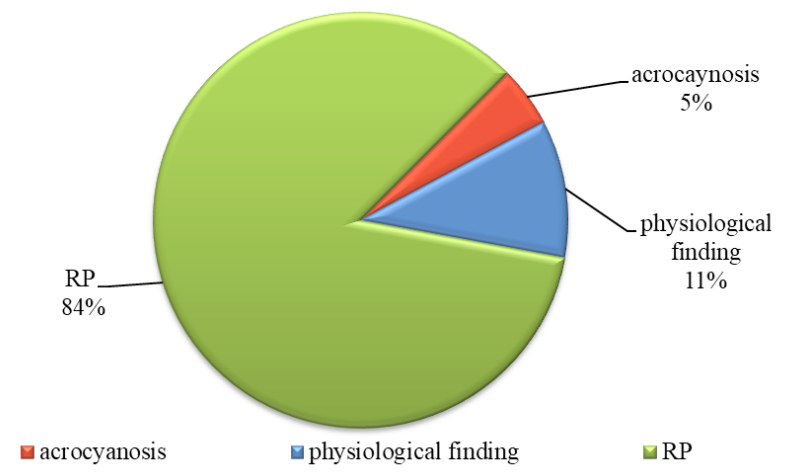

Fig. 4. Diagnosis according to IRT examination. with a lower $(29.3 \%)$ or higher $(24 \%)$ degree of pathology in the capillaroscopic examination (Fig. 5).

By summarising the results of the IRT and the capillaroscopic examination, five different groups of findings were found - physiological findings, acrocyanosis, PRP, borderline SRP, and SRP. The group of patients with physiological findings and acrocyanosis according to the results of the IRT examination was characterised by a physiological finding in the capillaroscopic examination. For the remaining groups of patients - PRP, borderline SRP and SRP - the IRT examination resulted in an RP finding; hence, they only differed in the results of the capillaroscopic examination. The PRP group was characterised by a physiological finding in the capillaroscopic examination. Patients with a mild pathology finding in the capillaroscopic examination were included in the borderline SRP group, and a pathological finding in the capillaroscopic examination meant a diagnosis of SRP. Based on the results of these two examination methods and statistical processing, $4.7 \%$ of patients were diagnosed with acrocyanosis, $10.7 \%$ with physiological findings, $31.3 \%$ with PRP, 29.3\% with findings suggesting borderline SRP and $24 \%$ with SRP. To simplify further statistical processing, these disease groups were merged into two principal groups - "secondary" and "other". The "secondary" group

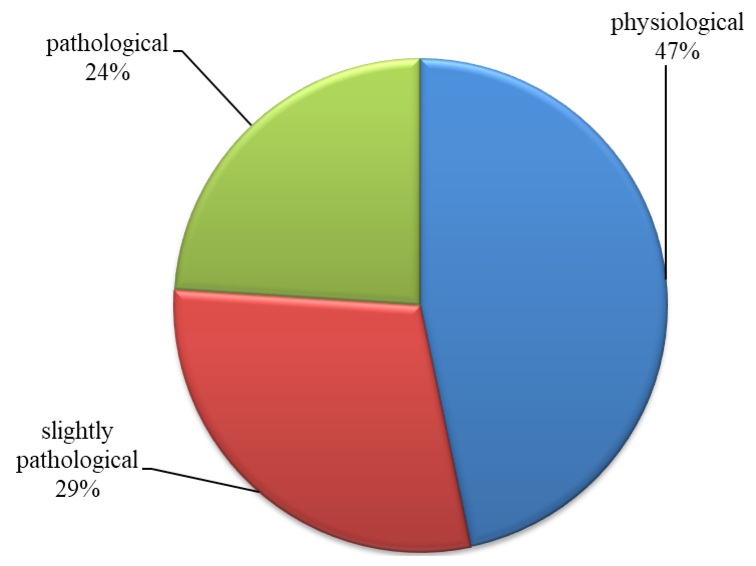

Fig. 5. Diagnosis according to capillaroscopic examination.

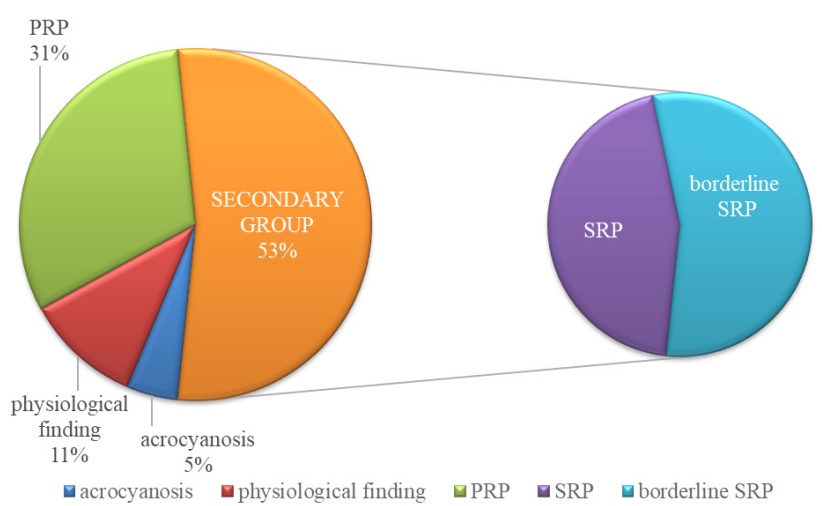

Fig. 6. Distribution of groups of findings according to the IRT results and capillaroscopic examination. 
included the SRP finding group and the borderline SRP group, while the "others" group included the PRP, acrocyanosis and physiological findings (Fig. 6).

In these two main groups, the incidence of three diseases, often associated with RP (thyroid disease, connective tissue diseases and neurological diseases), was statistically compared. According to Fisher's exact test, a significant dependence was shown between the occurrence of these diseases and the "secondary" group. Patients included in this group were significantly more likely to have connective tissue disease $(P=0.0001,35 \%)$ than those in the "other" group (5.7\%), which corresponds to the aetiopathogenetic context of connective tissue diseases. The other two - thyroid disease and neurological diseases - did not show any statistically significant differences in our group.

Comparing the number of fingers with a temperature of $\angle 29^{\circ} \mathrm{C}$ before passing the CPT, the Mann-Whitney U test showed a significant association between fingers with a temperature of $\angle 29^{\circ} \mathrm{C}$ and the inclusion of a patient into the "secondary" group $(P=0.006)$. A similar finding was established when monitoring the number of fingers with a temperature $<29{ }^{\circ} \mathrm{C}$ after passing the $\mathrm{CPT}(P=0.027)$.

When comparing the distal difference parameter values, no significant difference was established between the "secondary" and "other" groups.

In contrast, when the DDD parameter was monitored before the CPT, a significantly greater difference in the DDD values between the $2^{\text {nd }}, 3^{\text {rd }}$ and $4^{\text {th }}$ fingers of the right hand and the 3rd finger of the left hand in the "secondary" group was shown according to the Mann-Whitney U test.

After the CPT completion, a significantly higher difference in the value of the DDD parameter was shown only in the "secondary" group on the 5th finger $(P=0.030)$.

\section{DISCUSSION}

The dominant incidence of RP in female patients (77\%) (ref. $\left.{ }^{27,28}\right)$ corresponds to the epidemiological data from the examined population of patients. Interestingly, a typical triphasic progression of the disease attack occurred in only $22 \%$ of the patients, while only one colour change of the fingers (white or cyanotic) was reported by $33 \%$ of the patients. Establishment of an RP diagnosis by observing only one colour change according to Maverakis et al. is not sufficient under the RP diagnostic guidelines, and at least two observed colour changes are needed ${ }^{7}$. Taking into account the potential misinterpretation of finger colour changes by the patient and the benefit of the potential diagnosis of a serious illness at an early stage, it is also appropriate to include patients with a history of only one colour change in the examination. Of the total patient population, physiological findings were assessed in $10.7 \%$ of patients. One colour change was described in a total of $43.75 \%$ of this subgroup, which correlates with the aforementioned premise of it being better to examine a larger number of those that are healthy than a smaller number of individuals affected by the disease.
In the group under survey, RP was diagnosed in $84.7 \%$ of the patients by means of IRT. Such a high number is not a surprise because it is related to the specific nature of the examination that is performed on patients referred for the examination with already suspected RP. A higher morbidity of the patients sent for examination compared to the healthy population was also demonstrated by the fact that, in more than half of the patients in the group (53.3\%), the finding was evaluated as borderline SRP or SRP due to the capillaroscopic examination and the distal difference examination after the CPT. No effect of smoking has been statistically proven, which correlates with the results of the study by Palesche et al. ${ }^{29}$.

No relationship was established in the case of an asymmetric disorder, which is more often described in the diagnosis of SRP $\left(\right.$ ref. $\left.^{6}\right)$. Some authors have described the disorder of a thumb as significant for the diagnosis of SRP $\left(\right.$ ref. ${ }^{30,31}$ ). In our patient population, however, this hypothesis was not confirmed, and perfusion disorders of the thumb were observed in patients with both PRP and SRP. The 5th finger was assessed as the coldest finger before the CPT, likely due to its smaller volume and the fact that its temperature is more easily influenced by the environment. We believe that thermal exchange is less likely to be affected on a shorter time axis by thermal diffusion through the flow of blood; rather, it is more affected by thermal exchange between the environment and the whole volume of the finger. This phenomenon was evident even after the impact of cold, when the 5th finger warmed faster due to the ambient temperature than the $2 \mathrm{nd}$ and 3 rd fingers. In our patient population, these two fingers most often had the lowest temperature of all fingers 30 min after the CPT (more than 59\% of right hand fingers and $58 \%$ of left hand fingers). This finding is consistent with our clinical experience, where the symptoms of RP are most often reported on these two fingers, perhaps due to the increased sensitivity of nervus medianus' neural branches and generally higher neurovascular reactivity ${ }^{32}$.

In the context of monitoring the temperature changes of hands, several authors have measured the temperature of the hand ridge and compared this temperature to that of the distal finger phalanges. A difference in temperature of $>1{ }^{\circ} \mathrm{C}$ (fingers colder than the hand dorsum) testifies in favour of SRP (ref. ${ }^{20-22}$ ). In the "secondary" subgroup of patients, we compared the DDD parameter with the result of the capillaroscopic examination, which testified in favour of SRP. The results of our work support this hypothesis. On the 2nd, 3rd and 4th fingers of the right hand and the 3rd finger of the left hand, a pathological finding of DDD significantly correlated with a pathological finding in the capillaroscopic examination $(P=0.009-0.049)$. After the completion of the CPT, however, the importance of monitoring the DDD parameter disappeared, and the finding of pathological DDD was no longer statistically significant for diagnosing SRF. This deterioration of the distinguishing capability of DDD after completing the CPT is consistent with the finding made by Pauling et al. ${ }^{22}$. 


\section{CONCLUSIONS}

Being non-invasive, the IRT examination is a completely safe method for patients, and the results of the examinations show that CPT enables objective evaluation acral perfusion disorders.

The use of CPT is not appropriate for patients with diagnosed critical digital ischaemia or with already visible development of trophic defects on the fingers of both hands, where it might cause further significant progression of ischaemia. In these cases, a possible solution may be the use of the parameter to monitor differences between the hand dorsum temperature and the distal phalanges (DDD), which was a statistically significant indicator in our observation, testifying to SRP on four of ten fingers. In our opinion, however, a question remains about whether to continue the use of CPT as part of the SRP diagnostics. The use of CPT is meaningful in cases where the RP diagnosis is uncertain. In cases where SRP and PRP need to be distinguished, it is better to use IRT without CPT, while monitoring the temperature of distal phalanges only after acclimatisation, or to use the DDD parameter.

The algorithm for the examination of patients with cold hand sensations should be the first to include IRT examination as part of the screening exam. Then, according to the findings, it should be followed by additional examinations (test for autoantibodies or capillaroscopy). The capillaroscopic examination can focus more on the fingers, which showed a pathological finding in the IRT examination.

Pathogenic RP changes occur in the vascular system of body extremities, and clinical changes are propagated on the skin of the fingers of the hand. As RP can often be a symptom of other diseases (connective tissue disease, vibration disease, hypothyroidism, carpal tunnel syndrome, hepatitis, etc.), RP is a problem that may be encountered by a variety of specialists ${ }^{33}$. For these reasons, it is necessary to educate both professionals and the general public in order to recognise this symptom in a timely manner, to discover its cause and subsequently to introduce adequate treatment. In addition to being a diagnostic method, the IRT could also become a method for evaluating the success of RP therapy in the future. However, this requires its wider introduction into routine practice in specialised departments.

\section{ABBREVIATIONS}

CPT, Cold pressor test; DDD, Distal-dorsal difference; IRT, Infrared thermography; PRP, Primary Raynaud's phenomenon; RP, Raynaud's phenomenon; SRP, Secondary Raynaud's phenomenon.

Author contributions: JS: literature search and manuscript writing; MT: critical reading and manuscript revision; JZ: statistical data analysis.

Conflict of interest statement: None declared.

\section{REFERENCES}

1. Heidrich H. Functional vascular diseases: Raynaud's syndrome, acrocyanosis and erythromelalgia. Vasa 2010;39(1):33-41. doi:10.1024/0301-1526/a000003

2. Carpentier PH, Satger B, Poensin D, Maricq HR. Incidence and natural history of Raynaud phenomenon: A long-term follow-up (14 years) of a random sample from the general population. JVasc Surg 2006;44(5):1023-8. doi:10.1016/j.jvs.2006.07.037

3. Biskup E. Kalt und weiss - Hypothenar-Hammer-Syndrom. Praxis (Bern 1994) 2018;107(16):912-16. doi: 10.1024/1661-8157/a003046 (In German)

4. Ben Salem T, Tougorti M, Bziouech S, Lamloum M, Khanfir M, Ben Ghorbel I, Houman MH. [Etiological profile of secondary Raynaud's phenomenon in an internal medicine department. Approximately 121 patients]. J Med Vasc 2018;43(1):29-35. doi: 10.1016/j. jdmv.2017.11.00.

5. Knapik-Kordecka M, Wysokinski WE. Clinical spectrum of Raynaud's phenomenon in patients referred to vascular clinic. Cardiovasc Surg 2000;8(6):457-62

6. Tomcik M. [Raynaud's phenomenon]. Cas Lek Cesk 2016;155(6):31018. (In Czech)

7. Maverakis E, Patel F, Kronenberg DG, Chung L, Fiorentino D, Allanore Y, Guiducci S, Hesselstrand R, Hummers LK, Duong C, Kahaleh B, Macgregor A, Matucci-Cerinic M, Wollheim FA, Mayes MD, Gershwin ME. International consensus criteria for the diagnosis of Raynaud's phenomenon. J Autoimmun 2014;48-49:60-5. doi:10.1016/j. jaut.2014.01.020

8. Hughes M, Herrick AL. Raynaud's phenomenon. Best Pract Res Clin Rheumatol 2016;30(1):112-32. doi:10.1016/j.berh.2016.04.001

9. Stringer T, Femia AN. Raynaud's phenomenon: Current concepts. Clin Dermatol 2018;36(4):498-507. doi: 10.1016/j.clindermatol.2018.04.007

10. Naidu S, Baskerville PA, Goss DE, Roberts VC. Raynaud's phenomenon and cold stress testing: a new approach. Eur J Vasc Surg 1994;8(5):567-73.

11. Herrick AL, Murray A. The role of capillaroscopy and thermography in the assessment and management of Raynaud's phenomenon. Autoimmun Rev 2018;17(5):465-72. doi: 10.1016/j. autrev.2017.11.036

12. Kuryliszyn-Moskal A, Kita J, Hryniewicz A. Raynaud's phenomenon: new aspects of pathogenesis and the role of nailfold videocapillaroscopy. Reumatologia 2015;53(2):87-93. doi:10.5114/reum.2015.51508

13. Bernero E, Sulli A, Ferrari G, Ravera F, Pizzorni C, Ruaro B, Zampogna G, Alessandri E, Cutolo M. Prospective capillaroscopy-based study on transition from primary to secondary Raynaud's phenomenon: preliminary results. Reumatismo 2013;65(4):186-91. doi:10.4081/ reumatismo.2013.186

14. Koenig M, Joyal F, Fritzler MJ, Roussin A, Abrahamowicz M, Boire G, Goulet JR, Rich E, Grodzicky T, Raymond Y, Senécal JL. Autoantibodies and microvascular damage are independent predictive factors for the progression of Raynaud's phenomenon to systemic sclerosis: a twenty-year prospective study of 586 patients, with validation of proposed criteria for early systemic sclerosis. Arthritis Rheum 2008;58(12):3902-12. doi:10.1002/art.24038

15. Ascherman DP, Zang Y, Fernandez I, Clark ES, Khan WN, Martinez L, Greidinger EL. An Autoimmune Basis for Raynaud's Phenomenon: Murine Model and Human Disease. Arthritis Rheumatol 2018;70(9):1489-99. doi: 10.1002/art.40505

16. Rubio-Rivas $M$, Corbella X, Pestaña-Fernández $M$, Tolosa-Vilella C, Guillen-Del Castillo A, Colunga-Argüelles D, Trapiella-Martínez L, Iniesta-Arandia N, Castillo-Palma MJ, Sáez-Comet L, EgurbideArberas MV, Ortego-Centeno N, Freire M, Vargas-Hitos JA, RíosBlanco JJ, Todolí-Parra JA, Rodríguez-Carballeira M, Marín-Ballvé A, Segovia-Alonso P, Pla-Salas X, Madroñero-Vuelta AB, Ruiz-Muñoz M, Fonollosa-Pla V, Simeón-Aznar CP, Callejas Moraga E, Calvo E, Carbonell C, Castillo MJ, Chamorro AJ, Colunga D, Corbella X, Egurbide MV, Espinosa G, Fonollosa V, Freire M, García Hernández FJ, González León R, Guillén Del Castillo A, Iniesta N, Lorenzo R, Madroñero AB, Marí B, Marín A, Ortego-Centeno N, Pérez Conesa M, Pestaña M, Pla X, Ríos Blanco JJ, Rodríguez Carballeira M, Rubio Rivas $M$, Ruiz Muñoz M, Sáez Comet $L$, Segovia P, Simeón $C P$, Soto A, Tarí E, Todolí JA, Tolosa C, Trapiella L, Vargas Hitos JA, Verdejo G. First clinical symptom as a prognostic factor in systemic sclerosis: 
results of a retrospective nationwide cohort study. Clin Rheumatol 2018;37(4):999-1009. doi: 10.1007/s10067-017-3936-7

17. Kopová R, Šternberský J, Tichý M. Chilblain lupus - méně obvyklá varianta kožního erythematodu. Dermatologie pro praxi 2012;6(3):142-3. (In Czech)

18. Ring EFJ, Ammer K. Infrared thermal imaging in medicine. Physiological Measurement 2012;33(3):R33.

19. Ammer K. The Glamorgan Protocol for recording and evaluation of thermal images of the human body. Thermology international 2008;18(3):125-9.

20. Anderson ME, Moore TL, Lunt M, Herrick AL. The "distal-dorsal difference": a thermographic parameter by which to differentiate between primary and secondary Raynaud's phenomenon. Rheumatology (Oxford) 2007;46(3):533-8. doi:10.1093/rheumatology/kel330

21. Clark S, Hollis S, Campbell F, Moore T, Jayson M, Herrick A. The "distaldorsal difference" as a possible predictor of secondary Raynaud's phenomenon. J Rheumatol 1999;26(5):1125-8.

22. Pauling JD, Flower V, Shipley JA, Harris ND, McHugh NJ. Influence of the cold challenge on the discriminatory capacity of the digital distal-dorsal difference in the thermographic assessment of Raynaud's phenomenon. Microvasc Res 2011;82(3):364-8. doi:10.1016/j. mvr.2011.03.007

23. Cutolo M, Sulli A, Smith V. How to perform and interpret capillaroscopy. Best Pract Res Clin Rheumatol 2013;27(2):237-48. doi:10.1016/j. berh.2013.03.001

24. Andrade LE, Gabriel Junior A, Assad RL, Ferrari AJ, Atra E. Panoramic nailfold capillaroscopy: a new reading method and normal range. Semin Arthritis Rheum 1990;20(1):21-31.
25. Hartmann P, Mohokum M, Schlattmann P. The association of Raynaud's syndrome with carpal tunnel syndrome: a meta-analysis. Rheumatol Int 2012;32(3):569-74. doi:10.1007/s00296-011-2122-5

27. Nielsen SL, Parving HH, Hansen JE. Myxoedema and Raynaud's phenomenon. Acta Endocrinol (Copenh) 1982;101(1):32-4.

28. Freedman RR, Moten M. Gender differences in modulation of peripheral vascular adrenoceptors. Ann Behav Med 1995;17(1):15-18. doi:10.1007/BF02888802

29. Cooke JP, Creager MA, Osmundson PJ, Shepherd JT. Sex differences in control of cutaneous blood flow. Circulation 1990;82(5):1607-15.

30. Palesch YY, Valter I, Carpentier PH, Maricq HR. Association between cigarette and alcohol consumption and Raynaud's phenomenon. J Clin Epidemiol 1999;52(4):321-8.

31. Chikura B, Moore T, Manning J, Vail A, Herrick AL. Thumb involvement in Raynaud's phenomenon as an indicator of underlying connective tissue disease. J Rheumatol 2010;37(4):783-6. doi:10.3899/ jrheum.091117

32. Chikura B, Moore TL, Manning JB, Vail A, Herrick AL. Sparing of the thumb in Raynaud's phenomenon. Rheumatology (Oxford) 2008:47(2):219-21. doi:10.1093/rheumatology/kem353

33. Horikoshi M, Inokuma S, Kijima Y, Kobuna M, Miura Y, Okada R, Kobayashi S. Thermal Disparity between Fingers after Cold-water Immersion of Hands: A Useful Indicator of Disturbed Peripheral Circulation in Raynaud Phenomenon Patients. Intern Med 2016;55(5):461-6. doi:10.2169/internalmedicine.55.5218

34. Matucci-Cerinic C, Nagaraja V, Prignano F, Kahaleh B, BellandoRandone $\mathrm{S}$. The role of the dermatologist in Raynaud's phenomenon: a clinical challenge. J Eur Acad Dermatol Venereol 2018;32(7):1120-7. doi: $10.1111 /$ jdv.14914 